\title{
Escritores, relação com a escrita e experiência: um campo em educação artística ${ }^{1}$
}

\author{
Writers, relationship with writing and experience: a field in art \\ education
}

\section{Écrivains, rapport a l'ecriture et experience: un champ en education artistique}

\begin{abstract}
Paulo Nogueira ${ }^{2}$
Universidade do Porto, Portugal, Faculdade de Psicologia e de Ciências da Educação, Docente, Faculdade de Belas Artes, Docente do Programa de Doutoramento em Educação Artística, Investigador do Centro de Investigação e Intervenção Educativa (CIIE/FPCEUP) e Membro colaborador do Instituto de Investigação em Arte, Design e Sociedade
\end{abstract}

Resumo: $O$ objetivo neste ensaio é apresentar parte de um trabalho de interpretação resultante de uma investigação narrativa e biográfica realizada com escritores portugueses, cujo objeto incidiu na "relação com a escrita" (20062012). Tal trabalho constituiu-se numa exploração biográfica das narrativas de vida de Manuel António Pina, Mário Cláudio, Ana Luísa Amaral, Luísa Dacosta e Jorge Velhote, no âmbito da qual procurou se aceder ao cosmos vivencial que foi e é a atividade de escrita daqueles escritores e, no contexto mais vasto, dos seus itinerários de vida literária e educativa. A abordagem em torno dessa questão, mesmo se já alguns anos passados desde que a construímos, continua a permitir-nos refletir a respeito dos movimentos singulares que tecem os modos de viver a experiência da escrita. Tendo por base esse quadro, com o presente texto pretendemos contribuir para alguma reflexão em educação artística.

Palavras-chave: Interpretação. Experiência. Relação com a escrita.

Abstract: The purpose of this essay is to present part of a narrative and biographical research held with portuguese writers, focused on the relationship with writing (2006-2012). This research consisted in a biographical exploration

\footnotetext{
Este texto resulta de uma comunicação apresentada ao Congresso Internacional \# 16.ART: Artis intelligentia: Imaginar o Real, realizado entre os dias 11 e 14 outubro de 2017 na Faculdade de Belas Artes da Universidade do Porto, Portugal. Uma parte deste texto consta do livro de atas do referido Congresso. $\bigcirc$ ensaio agora aqui publicado corresponde a uma versão ampliada da comunicação aí apresentada.

2 Doutor em Ciências da Educação pela Universidade do Porto.
} 
of the life narratives of Manuel António Pina, Mário Cláudio, Ana Luísa Amaral, Luisa Dacosta and Jorge Velhote, through witch we've interpreted the "experiential cosmos" of their writing activity in the wider context of his literary and educational itineraries. The approach on this issue, even if some years passed since I built it, continues to allow us to reflect on the singular movements that link the ways of living the experience of writing. From the point of view of the writers, and challenging new ideas about learning and writing, this paper aims to contribute to some of the reflection in art education.

Keywords: Interpretation. Experience. Relationship with writing.

Résumé: Le but de cet essai est de présenter une partie d'une recherche narrative et biographique avec des écrivains portugais sur le rapport à l'écriture (2006-2012). Cette recherche a consisté à l'explora tion biographique des récits de vie de Manuel Manuel António Pina, Mário Cláudio, Ana Luísa Amaral, Luísa Dacosta et Jorge Velhote, à travers lequel nous avons interprété le cosmos expérientiel de leur activité d'écriture dans le contexte plus large de ses itinéraires littéraires et pédagogiques. L'approche sur cette question, même si quelques années écoulées depuis que je l'ai construit, continue de nous permettre de réfléchir sur les mouvements uniques qui relient les façons de vivre l'expérience de l'écriture. Du point de vue des écrivains, et en contestant des idées sur l'apprentissage et l'écriture, cet article vise à contribuer à la réflexion en éducation artistique.

Mots-clés: Interprétation. Expérience. Rapport à l'écriture.

\section{NOTA PRÉUIA}

A abordagem aqui apresentada em torno das questões da educação artística e da "relação com a escrita" surge enquadrada por um projeto de investigação realizado entre 2006 e 2012. Muito embora tal projeto tenha configurado um percurso próprio do ponto de vista das questões que na altura o sustentaram, é com base na racionalidade metodológica e interpretativa que nele ensaiamos que para este texto propomos uma reflexão agora mais circunscrita ao contexto da presente publicação. Com efeito, se na altura pretendemos construir 
um campo de exploração biográfica em torno das narrativas de vida de um grupo de escritores portugueses, na verdade foi a partir de tal intenção, e à custa também do que constitui o meu campo de ação ligado ao ensino da escrita e à educação artística, que, nos últimos anos, aquele material narrativo tem vindo a assumir outras significações e, até mesmo, outras linhas de fuga. É com base nalgum questionamento produzido a partir do campo da educação artística que este texto problematiza uma ideia de "relação com a escrita" entendida como o lugar da experiência, esse "espaço do acontecer", como Larrosa (2002) o concebe. E porque qualquer movimento que traz em si uma proposta de problema é também um movimento de reinterpretação das suas origens, este texto volta a situar uma parte do seu universo teórico numa concepção de escrita cujo campo semântico se inscreve, sobretudo, num espaço de produção de tensões em face ao domínio das suas representações e ao sentido, frequentemente dogmático e utilitário, construído a propósito das suas práticas. Assim, e para o contexto deste ensaio, não sendo possível abarcar a totalidade dos retratos biográficos que estiveram na gênese do referido estudo, ${ }^{3}$ apresentarei apenas alguns aspectos relativos ao trabalho interpretativo levado a cabo, na expectativa de que esse breve apontamento contribua para o campo das práticas de investigação em educação artística, designadamente aquelas que se ocupam das questões da escrita e da experiência.

\section{PROBLEMA NARRATIUO}

Lembrando Benjamin (1992), é comum a todos aqueles que "vão colher o que se narra à experiência", isto é, a todos aqueles que se dizem "narradores", o "à-vontade" com que se movem pelos vários graus da experiência (sua e dos outros), "como quem sobe e desce uma escada". Ao revestiremse de histórias, as experiências de "vida literária" e de "vida educativa" dos escritores entrevistados, inscreveram-se num texto biográfico (oral, mental,

\footnotetext{
3 A leitura completa e detalhada desses retratos biográficos pode ser feita numa publicação posterior à conclusão do referido estudo. Cf. Nogueira (2015).
} 
escrito). Esse pressuposto veio situar-se num território de compreensão e análise, cuja lógica, superada a fobia racionalizante de preceitos universais, fez eco das derivações hermenêuticas e fenomenológicas nas quais, e já desde Dilthey, subjaz uma construção para o sentido da experiência humana singular. Esse foi um dos motivos pelos quais se decidiu desenvolver uma interpretação narrativa dos textos recolhidos por meio de entrevista biográfica, como mais adiante assinalaremos. Pareceu-nos constituir uma relevância acrescida a operacionalização da entrevista à luz das suas potencialidades narrativas, mais ainda, talvez, quando numa investigação com escritores estaria em jogo a interpretação da sua própria relação "narrativa" com a escrita. De fato, os escritores são poderosos narradores do tempo, ao mesmo tempo que por ele são narrados, e pelas referências do pensamento literário do tempo do qual fazem parte. Tornou-se disso um exemplo, em diferentes situações narrativas, a referência feita à influência das leituras dos existencialistas, dos pós-estruturalistas, dos autores considerados "clássicos", o interesse pela discussão científica, entre outros aspectos. A complexidade interna a esse universo narrativo, profundamente mediado e interpretado pelos próprios, é produtora de uma forte instabilidade no campo da interpretação e da análise (para não dizermos ilusão) biográfica. Com efeito, uma parte significativa das histórias pessoais contadas pelos escritores parece surgir como uma herança de todos, bem como de todas as personagens a que pertencem e que, de forma mitológica, as constituem. Em termos de análise, essa questão levantounos o conflito existente entre, por um lado, o domínio técnico da biografia (o seu processo de contar, de análise, de reconstrução, etc.) e, por outro, o seu domínio artístico, já que parece ser à custa de uma ideia de literatura concebida enquanto gênero, e também em razão da forte tradição da narrativa no campo literário, que uma certa concepção de "biografia" parece se consagrar no espaço social (ela é sempre mais imaginada do que pensada, mais ficcional do que real, mais romanceada do que vivida, etc.). Nessa tensão entre um polo técnico e um polo artístico nos modos de conceber a biografia (nesse caso, como gênero de escrita da vida) subjaz, com efeito, não só o estatuto que se queira conceder ao romance enquanto forma privilegiada de relato, como a diferença que se estabelece, para o biógrafo, entre história e ficção. E, todavia, todas as efabulações contemporâneas, desde Homero, não são anônimas. As 
suas criaturas têm autores, particularmente se forem personagens históricas, cuja realidade, além de coletivamente interpretada, é constituída pelas histórias que subsistem no seu interior. Por essa razão, mesmo transformada num objeto estético (ou sendo-o), uma história não perderá nunca uma relação com o real, porque ela possui em si um potencial de agência no processo histórico mais vasto, bem como na história que aí é narrada. Esse aspecto parece ganhar outra dimensão, se pensarmos que, não só hoje em dia, como desde sempre, as fronteiras entre mundos considerados ontologicamente distintos (vida e morte, verdade e mentira, sonho e realidade, etc.) correspondem a categorias em constante superação, e não só por aqueles que escrevem uma literatura considerada imaginativa ou se assumem como autores de biografias; dir-se-ia que a própria narrativa histórica assim o experimenta e testemunha.

Contudo, a entrevista que levamos a cabo não teve por objetivo compreender de que maneira aquelas fronteiras são violadas pelas narrativas (e narrações) dos escritores. Ela não se constituiu enquanto "entrevista de literatura", nem sobre a obra em si, ou ainda menos sobre o "delírio" que se implica na relação entre "vida e obra" do escritor. Pelo contrário, os actos pelos quais os escritores relataram uma "história da vida" são, na perspectiva que adoptamos, uma representação subjetiva de como o seu sentido histórico se estabelece/desvanece permanentemente nessa tensão. Nessa medida, e do ponto de vista da investigação, as ideias de "obra", "gênero", "romance" ou "livro", se numa primeira percepção poderiam surgir enquanto vias privilegiadas para o trabalho de interpretação, na verdade tais elementos se tornaram insuficientes para uma lógica de ação interpretativa, cuja performance passou, essencialmente, a considerar as formas literárias (e o seu trabalho) nos contextos sociais, vivos. Dessa maneira, e porque tal se constituiu igualmente num problema de análise, tornou-se significativo, para o intérprete, compreender de que modo os itinerários literários dos escritores se situavam num determinado campo do poder (cultural e artístico), e dele fundamentalmente vão sendo um resultado enquanto manifestação, prática social e crítica.

Olhando para esse campo de tensões, as propostas de investigação biográfica com escritores constituem-se num reentrante questionamento quanto às suas próprias condições de possibilidade. $\bigcirc$ investigador surge também ele 
mediado pelos tempos e espaços narrativos dados pelo autor da narrativa, um autor que é simultaneamente empírico e textual, para além de intérprete literário de si mesmo (NOGUEIRA, 2015). Um trabalho de investigação que tome por objeto empírico experiências narradas por escritores (sendo, no entanto, de considerar a posição literária e a construção narrativa que, por meio da "ideologia da obra", nalguns escritores possuirá uma dominante institucional de maior peso) vê-se sujeito a lógicas de conhecimento cujas tensões metodológicas se manifestam no interior do próprio campo da investigação biográfica e das suas gramáticas narrativas dominantes. Na verdade, o processo de investigação veio constituir-se, ele próprio, num texto cujo espaço de "dispersão e travessia", diria Barthes (1975), exigiu relações distintas e, muitas vezes, opostas, entre o campo da atuação metodológica e o campo da interpretação.

\section{NUM JOGO SOBRE O SIGNIFICANTE}

Contudo, foi justamente no interior dessa tensão epistemológica que os relatos de vida dos escritores foram sujeitos a um trabalho de projeção gráfica, cujo conteúdo, à luz da racionalidade adotada, assumiu diferentes hipóteses de biograma. Como recurso de interpretação e análise de dados biográficos, nos termos de Denzin (2001), o trabalho de elaboração de um conjunto de biogramas traduziu-se num processo pelo qual se representou o universo de dados cronológicos e as diversas situações de vida (literária e educativa) implicadas nas trajetórias individuais dos escritores. Aos olhos do intérprete, essa possibilidade de leitura permitiu visualizar o desenho dos próprios textos. Enquanto projeção gráfica, os biogramas permitiram ler um conjunto de (des) continuidades temporais à volta da valoração que os narradores foram dando a certos intervalos cronológicos, marcados principalmente pelos tempos relativos à infância, às mudanças de cidade (o nascimento, a casa familiar, o liceu, a casa universitária, a casa profissional, etc.) e à própria prefiguração de uma ideia de trajetória que daí surgiu. Este trabalho trouxe-nos potencialidades heurísticas num primeiro momento impensadas. A tarefa de construir, pelo acesso a um certo quadro gráfico subjacente ao mapa biográfico que nos foi 
narrado por cada um dos escritores, refletiu-se num ato pelo qual o intérprete ia lendo as narrativas de vida, no sentido em que tais narrativas se encontravam paralelamente situadas numa imagem mental que o investigador foi captando, reconfigurando-as permanentemente. Se quisermos assumir tal projeção enquanto texto, o biograma veio permitir não só a reconstrução cronológica de um tempo pelo qual a vida dos escritores foi narrativamente acontecendo, mas sobretudo a valoração, dada pelos relatos, acerca dos principais eixos (biográficos e temáticos) organizadores da narrativa.

Por outro lado, a sua construção não se fez independentemente daquilo que poderíamos dizer ser os "estilos narrativos" (orais e textuais) de cada um dos escritores ao falarem das suas experiências de vida. Na verdade, tais biogramas não possuem um mesmo esquema gráfico, já que cada um deles se constituiu num ato particular de escrita. Os estilos narrativos dos escritores, ao falarem da vida, incorporam tonalidades distintas, traços mais ou menos estruturados de falar, ritmos que diferem entre si. Eles desenham, nesse espaço, um determinado movimento discursivo, não só por meio da entoação, do silêncio e dos diferentes tons narrativos, mas antes, e simultaneamente, pela representação simbólica, a qual, enquanto narrativa, veio inscrever-se no pensamento. A projeção gráfica que resulta dessa inscrição da narrativa ao nível da consciência correspondeu a uma resposta que o investigador pôs em papel (originada que é por uma imagem) da trama narrativa no seu conjunto e das personagens que nela surgiram (NOGUEIRA, 2015). Os biogramas são simultaneamente jogos gráficos de leitura narrativa e de valoração interpretativa das principais (des)articulações subjectivas pelas quais a vida dos escritores narrativamente se joga. Uma vez que essa valoração difere de escritor para escritor, ao nível do movimento discursivo que em si desenha não nos foi possível desenhar uma mesma projecção gráfica (no sentido de esquema ou quadro) relativa à concepção dos seus mundos. Mas como representações derivadas de imagens pertencentes ao imaginário coletivo, o investigador recorreu a representações pelas quais as "metáforas vivas" do pensar a vida, diria Ricoeur (1996), no fundo, e simbolicamente, "aparecem", e no âmbito das quais, ainda, relacionam-se diversos polos opostos e complementares entre si. Nessa medida, dos biogramas vimos surgir as representações de algum 
modo arquetípicas no âmbito das quais subjaz a racionalidade moderna de, desviando-a, desenhar a vida. Eles deram corpo a diferentes projeções, entre o modelo da "cruz" (orientada pelas forças e peso dos pontos cardeais), o modelo "circular" (de cuja representação cultural surge a ideia de um labirinto, interna e externamente percorrido) e o modelo da "coluna" (o qual permitiu uma leitura simultaneamente horizontal e vertical).

O imperativo da diversidade que emergiu de cada uma das projeções gráficas que realizamos se prende, na nossa perspectiva, com todos os fenômenos (na acepção fenomenológica) que se implicam na tradução do oral em escrito. De fato, na mediação aí implicada, há um fenómeno de natureza mental, pelo qual o investigador visualiza os movimentos (pelo vaivém das linhas) e os principais quadros cronológicos que fazem convocar as personagens que compõem a trama. Pela sua centralidade nas narrativas de vida, as personagens em cada um dos biogramas foram evocadas na sua amplitude biográfica maior (elas são "pessoas" e "protagonistas literários"), uma vez que, nos modos e estilos narrativos de cada escritor, elas surgiram com o mesmo equilíbrio narrativo. Como participantes numa intriga, e que acompanharam os processos de transição dos escritores-alunos, em escritores-professores e em escritoresartistas, o lugar ocupado por tais personagens ajudou a pesar a simetria narrativa para o lado das suas principais performances - são personagens familiares, escolares, literárias, de cinema, personagens profissionais, figuras que marcaram "o acesso ao campo literário", de "viragem" sob o ponto de vista do eco que tiveram nas histórias pessoais. Nessa medida, elas surgiram nos biogramas vinculadas à valoração que possuíram na produção dos relatos. Como projeções - porque corresponderão a formas "bidimensionais" de tradução gráfica do pensamento - os biogramas permitiram-nos entrar num universo biográfico e compreender de que modo a procura de significação que é posta pelos escritores nos textos que oralizaram sobre a vida pode condensar uma lógica, cuja leitura veio a se constituir, aos olhos do intérprete, num jogo sobre o significante. Uma vez que qualquer narrativa incorpora uma teorização sobre esse constructo simbólico que é a vida, os modelos adotados para elaborar os biogramas traduziram as formas pelas quais ocorreu a procura de um equilíbrio vital, cuja racionalidade, numa "história da vida", pareceu-nos uma constante. 
Desse modo, na textura global do texto que o investigador produziu enquanto retratos autobiográficos dos escritores, surgiram atravessadas as articulações narrativas em que se jogaram os seus planos de vida. São elas a peregrinação e a estabilidade, em Manuel António Pina, a a autonomização e o investimento, em Mário Cláudio, o pesadelo e o paraíso, em Ana Luísa Amaral, a história, a pedagogia e a literatura, em Luísa Dacosta, e a vida profissional e a vida literária, em Jorge Velhote. ${ }^{4}$

\section{DESUIOS E NÓS}

Uma vez que aquele estudo se ocupou de narrativas biográficas de escritores centradas na "relação com a escrita", o trabalho metodológico desenvolvido, ao assentar no imperativo da interpretação, justificou-se à luz dos derivados narrativos que vimos surgir ao longo do processo de entrevista. ${ }^{5}$ A mediação entre os tempos que pudemos encontrar nos retratos autobiográficos dos escritores se estruturou à volta daquilo que poderíamos chamar um triplo entrecho, dado, na sua singularidade, esses tempos prefigurarem, configurarem e reconfigurarem um nexo de experiências de vida como escritores, cujas ações se desenrolaram nos papéis de alunos, professores e artistas em Portugal. Tais "ações" - convocando-se aí as transformações sociais, culturais e políticas que se atravessaram antes e após o 25 de abril de 1974 - encontram-se balizadas pelos períodos que marcaram o início das suas relações com a escrita e com um certo universo literário que marcou a identidade desse período na cultura portuguesa e nos seus modos de expressão pública e artística. No contexto desse cenário, quisemos justamente singularizar o esboço biográfico feito pelo próprio

\footnotetext{
4 desenho desses biogramas pode ser consultado na publicação referida em nota anterior (Nogueira, 2015).

5 O processo da entrevista constituía-se, apenas, por um tema gerador (Gostava que me falasse sobre as suas memórias de escrita), a partir do qual os itens "esboço biográfico geral", "territórios e contextos de escrita", "itinerários e deontologias" e "síntese" foram, ao longo das conversas e dos encontros realizados, gravitando ao seu redor. Os tempos e os espaços de realização desse processo inscreveram-se nas próprias rotinas da investigação, segundo uma lógica, não só desenhada em função da personalidade de cada narrador, como flutuante ao longo do período que marcou o início e o fim da totalidade das entrevistas (outubro de 2008 a março de 2010).
} 
escritor, sendo tal esboço também ele atravessado pelas memórias dos lugares, bem como das personagens e das vozes (políticas e literárias) com as quais cada um cresceu e se debateu. É tendo por base uma concepção de intriga que fomos ler em Ricoeur (1983) que a configuração das suas narrativas resultou nesta ideia de retratos autobiográficos pensados como um todo diferenciado e numa síntese plural de eventos discursivos. Assim, considerou-se que as suas trajetórias se constituíram narrativamente à volta de um conjunto de relatos de vida cultural, educativa e literária, em que os próprios acrescentaram acontecimentos de especial significação pessoal e social, como "a publicação (do "primeiro livro" e não só)"; "quando eu fui professor"; " a aprendizagem, e as experiências de escrita, na escola"; "a experiência da leitura"; "as memórias de infância"; "as atividades profissionais paralelas à atividade de escrita"; "a formação acadêmica"; "a relação com a cidade e as viagens"; "as relações com o campo da vida literária". Tais significações pessoais não se estruturaram nem sob o ponto de vista da sua narração oral, nem sob o ponto de vista da fixação em texto que o investigador lhes deu, segundo um eixo temporal diacrônico. Elas constituíram-se, assim, à luz da racionalidade da investigação biográfica e narrativa, em "pontos de inflexão" (um termo de algum modo alternativo ao de "epifania"), por meio dos quais se deslindaram as atribuições de valor positivo e negativo de determinadas experiências nas suas vidas, vividas enquanto escritores.

Terá sido desse modo que, como intérpretes, fomos situando nos discursos dos escritores fixados em texto um conjunto diverso de "desvios narrativos", isto é, tudo aquilo que, na narrativa, desmesurou as categorias de tempo e espaço, mas também tudo aquilo que, não tendo vindo a propósito do objeto formulado pela questão da entrevista (gostava que me falasse das suas memórias de escrita), acrescentou e produziu um sentido implícito, como, por exemplo, as leituras em voz alta que alguns escritores fizeram de alguns livros seus e de outros, ou as suas observações pessoais relativas à ciência, à arte ou à pedagogia. $\bigcirc$ processo pelo qual tais desvios se identificaram e marcaram nas narrativas se traduziu num trabalho, o qual permitiu que a produção e a transformação de um sentido narrativo como escritor se fosse alterando e definindo à medida que o fomos reescrevendo. Em traços gerais, tais desvios também se corporalizaram em todos os momentos pelos quais os 
escritores foram falando de tudo, menos - objetivamente - de "relação com a escrita". Mas, no entanto, e procurando-se interpretar esses "desvios" à luz de uma ideia de performatividade, eles emergiram na narrativa enquanto nós do próprio discurso. Nessa medida, não só diferentes entradas no texto puderam ser feitas, como, por meio de uma espécie de evasão, a narrativa pareceu adquirir um sentido de história pessoal. Recorreu-se, assim, à interpretação e à reescrita de tudo o que surgiria afeto a uma personal story, a qual, muito embora situada e recontada inúmeras vezes pelos próprios (os escritores, por diversas vezes, e noutros contextos, já se viram a falar sobre o papel da escrita e a relação que com ela mantêm, para além de a recontarem para si próprios em inúmeras circunstâncias e vozes), pôde, apesar disso, dar lugar a um sentido de continuidade diferente, dada a própria lógica de empreender a entrevista biográfica segundo uma temporalidade espaçada entre intervalos de meses. Nos seus textos autobiográficos, surgiram, assim, as próprias performatividades inerentes aos seus modos de falar, como sejam os comentários que foram fazendo como que dialogando com narradores aí presentes, e no contexto dos quais convocaram diferentes argumentos, gestos, interjeições, diálogos com outras personagens, etc., vindo a conferir-nos uma estrutura temporal "móvel" e uma qualidade performativa ao que nos contaram (NOGUEIRA, 2015). No nosso ponto de vista, tal texto performativo no qual resultou este primeiro trabalho de interpretação não pode ser pensado fora do quadro verbal no qual esses escritores se situam enquanto "operadores da linguagem", isto é, procurouse produzir um texto de tipo performativo, mas em que nele sobreviesse a qualidade comunicativa dos próprios escritores. Nessa medida, tal trabalho interpretativo correspondeu a um território onde se fixaram as marcas desse primeiro texto dito e inscrito pelos próprios, território esse, para evocarmos os termos de Genette (1982), próximo de uma "literatura de segundo grau".

\section{DO EDUCATIUO E DO LITERÁRIO}

As experiências narradas pelos escritores e os seus pontos de vista estético-pedagógicos quanto aos valores que atribuem à "relação com a 
literatura" - e às oposições que dela veem surgir quando tomada no quadro das suas experiências literárias escolares - permitiram-nos aprofundar as várias e possíveis ligações que se manifestam na relação de um sujeito com o objeto escrita, isto é, as suas "colorações" várias e imprevistas, aproveitando uma expressão de Penloup (2000). Assim, uma abordagem pelo lado da "relação com a escrita", permitindo desfazer e alargar um conjunto de clivagens sobre o objeto escrita (idem), deu-nos a conhecer as múltiplas relações que nela se podem manifestar, procurando-se sublinhar, pelo lado das narrativas dos escritores, as tensões e as oposições dialéticas que se implicam nos processos de produção escrita.

Desse modo, e procurando fazer associações de sentido entre os valores do educativo e do literário, entendi que o campo educativo - visto aqui como o campo das experiências culturais, das memórias sociais e das histórias educativas - é um campo literário, não só em virtude da dimensão narrativa da educação, mas porque se trata de um campo fundado na experiência e nos fenômenos de relação com o saber, esse patrimônio de que se constituem as imagens do pensar e do agir humanos. Assim, o sentido do "educativo" naquele estudo relacionava-se, por um lado, com uma forte dimensão narrativa (isto é, o que é que a experiência de vida de uma pessoa possui para nos contar?) e, por outro, existencial, não propriamente segundo uma matriz existencialista, mas mais no sentido das diferentes existências às quais a experiência da educação pode dar corpo.

A concepção dos escritores enquanto produtores e agentes do campo educativo tem por consequência não podermos ignorar em que medida estudar as suas memórias e os seus discursos narrativos em torno da escrita pode trazer, nesse caso do ponto de vista de uma educação artística, uma interrupção diante da perspetiva de olharmos a questão educativa da escrita pelo lado das histórias contadas por professores e/ou alunos sobre os seus "usos escolares". Nessa perspectiva, as narrativas de vida de escritores podem emergir não só como um modo mediante o qual se problematizam os seus fenômenos de identificação social (objeto do qual uma sociologia da arte parece se ocupar), mas também como um processo de se investigarem os modos de "relação com a escrita", e em que medida tais experiências narradas por escritores podem ser reinterpretadas à luz dos seus valores educativos mais amplos, ao mesmo tempo 
que tais relatos se convertem numa poderosa crítica, não só literária, como, em grande parte, artística e pedagógica.

Considerando esse conjunto de pressupostos, entendi que o sentido educativo deste trabalho de interpretação tem justamente que ver com o modo pelo qual a escrita é perspectivada, isto é, inseparável, diria Gadamer (2000), da "linguisticidade da experiência do mundo". Ora, em qualquer prática de escrita, seja de que tipologia for, é estabelecida uma "relação com a escrita" (variável de sujeito para sujeito e além disso variável ao longo da vida), mas à qual o sujeito atribui um saber de experiência. $\bigcirc$ educativo, nesses termos, tem que ver, então, com a percepção e o sentido do trabalho que é realizado e investido à volta desse saber. Ao recorrermos a uma expressão como esta, "relação com a escrita", estamos desde logo a abrir um campo semântico que vai no sentido de explorar as múltiplas variações e as ligações (conscientes e inconscientes) de um sujeito à escrita, salientando a indissociabilidade entre as dimensões do individual e do social que se atravessam no sentido do sujeito. A propósito, torna-se inevitável considerar as palavras de Peter Handke, já comentadas por Larrosa (1999), quando, num ensaio de 1967, e ao referirse ao "lugar" que a escrita ocuparia na sua experiência, Handke (1967 apud LARROSA, 1999, p. 127) diz:

[...] não tenho temas favoritos de [escrita], não tenho mais do que apenas um tema: ver claro, mais claro em mim mesmo, aprender a me conhecer, aprender o que faço sem me dar conta, o que penso sem me dar conta, o que penso sem reflectir, o que digo sem reflectir, o que digo por automatismo, o que os outros também fazem, dizem e pensam sem reflectir: chegar a ser atento e provocar atenção, provocar sensibilidade e chegar a ser mais sensível, mais receptivo, mais preciso, para que eu e os outros possamos também existir de maneira mais precisa e mais sensível, para que eu possa me entender melhor com os outros e ter melhores relações com eles. "Eu habito uma torre de marfim".

Ao decidirmos por uma abordagem pelo lado da "relação com a escrita", quisemos assumir um sentido de escrita enquanto construção subjetiva, e não tanto a ideia de uma prática assente na representação que sobre ela o 
sujeito detém, à maneira de uma situação de enunciação discursiva da qual não participa. Por conseguinte, as narrativas de vida dos escritores interessavam-nos por, e dada a subjetividade nelas implicada, deslocalizarem o sentido de uma relação com a escrita que é tida quase sempre na sua versão escolarizada. Isto não quer dizer que a escrita - o seu valor literário, o sentido da sua prática e da sua aprendizagem - não seja, em grande parte, determinada pelo universo das experiências escolares, e por isso é que o domínio das representações sobre a escrita continua a ser aquele que mais habita na tradição das suas práticas pedagógicas. Porém, existem dimensões extraescolares da vida que nos interessava discutir nessa relação dos escritores com a escrita, no âmbito das quais o sentido e o valor do literário surgissem narrados fora do discurso tendencialmente escolarizante acerca do seu ofício. Nesse aspecto, pelo acesso a um conjunto de memórias, as narrativas dos escritores vieram acentuar uma relação com os valores do literário cuja natureza não pertencerá apenas a vínculos escolares. Se na verdade tais valores narrados pelos escritores configuraram uma crítica artística à tradição escolar e estilística da escrita, eles surgiram igualmente enquanto crítica literária e política ao crescente modelo de escolarização cultural que hoje em dia parece dominar os discursos sobre a escrita e a literatura (a canonização operada pelos media literários, a ideologia do livro curto, a "vocação pedagógica" assumida pelos catálogos das editoras, a formalização de uma ideia de gosto, a apologia escolar do resumo, etc.), com implicações em nível de uma certa didatização da experiência.

E, todavia, os processos de escrita são processos que convocam o sujeito - a sua ação, a sua inscrição, o seu trabalho - na sua totalidade, isto é, um "todo eu que escreve". Significa isto que nos reportamos a um sujeito que, sob o ponto de vista da educação e da formação, é entendido na sua autoridade na relação com os produtos escritos, o que necessariamente vem implicar uma concepção da pedagogia, e das práticas da aprendizagem, mais à volta de um trabalho crítico sobre os próprios valores que dominam as ideologias do "aprender a escrever". Uma abordagem educativa em torno da "relação com a escrita" veio permitir refletir no sentido dos seus fins (o problema do "porquê escrever", isto é, o movimento que conduz a passagem do sujeito à escrita), sendo esta uma questão à qual veio se impor outra noção de aprendizagem, 
bem como outro ponto de partida, sob o ponto de vista dos processos educativos que aí podem se gerar, acerca do trabalho de escrita. Com efeito, enquanto o espaço da escrita continuar a ser encarado do ponto de vista das práticas escriturais superiores ("a verdadeira literatura"), continuará do mesmo modo, e designadamente nos processos de educação e formação de tipo escolar, a persistir a clivagem entre aqueles que são vistos como "escritores" (experts) e aqueles que, aparentemente desapossados desse "desejo intrínseco de escrever", são tidos como não escritores e, portanto, sem "autoridade" discursiva para na escrita fazerem reinar o seu talento literário e linguístico. Ora, não só no seu conjunto as narrativas dos escritores darão conta de uma relação com a escrita, a qual, sob o ponto de vista das suas experiências educativas, estará para além do discurso dos "talentos literários" ao qual muitas vezes a ideia do trabalho "sério" de escrita parece ficar reduzida (o que não quer dizer que a lógica da "inspiração" tenha deixado de ocupar aí um sentido singular), como, e do ponto de vista do que aqui queremos fazer notar, tal relação é concebida no quadro de uma contínua emergência ao longo da vida. A escrita vivida como uma "emergência contínua" ao longo (e a par) da vida dos escritores é simultaneamente concebida como uma experiência pessoal de aprendizagem e um saber que terá sempre em vista o saber dominar diferentes "registros de escrita". De fato, sob o ponto de vista das suas trajetórias subjetivas, não parece existir nunca um domínio global da escrita; ela é uma força que muitas vezes surge desconhecida. É por essa razão que, no que toca às gramáticas escolares da escrita, os escritores parecem colocar-se ao lado das perspectivas que defendem uma outra abordagem ao "ensino da literatura", cujas exigências implicam a integração de um movimento de saberes assumido pelo professor (e aqui o entendo enquanto produtor cultural comprometido com as limitações impostas pelo conhecimento), tratando-se, assim, de um gesto não só mais de acordo com o sentido da experiência do sujeito que aprende, como, e sobretudo, não negligenciando a eventual emergência de uma "tentação do literário", tentação essa, de resto, frequentemente ameaçada pelos discursos eleitos na sala de aula quando o assunto são os gênios ou os criadores literários.

Falar-se de uma tentação do literário é diferente, porém, da lógica pela qual a ideologia das vocações naturais em literatura muitas vezes se refere 
a alunos que aparentemente nascem escritores, ou misteriosamente tornam-se capazes de dominar os seus segredos. Tais alunos, segundo aquela ideologia, passam a ser inscritos, e à luz da racionalidade didática tradicional, na exclusividade do "polo literário" da escrita. Não sendo uma "coisa passageira", a escrita para esses alunos é referida a uma ordem estética e artística, enquanto num polo oposto, no "polo ordinário", parece inscrever-se a grande maioria dos restantes, cuja aprendizagem da escrita terá por finalidade transitiva "o saber comunicar" e o "saber expressar" (NOGUEIRA, 2015).

Nessa medida, tornar-se-á imperativo repensar os ofícios de escrita no contexto de uma educação artística que supere as tradicionais dimensões do comunicativo e do expressivo. Sob esse ponto de vista, qualquer que seja o trabalho de escrita feito num contexto de educação, ele poderá constituirse, em última instância, num trabalho a incidir sobre o próprio sujeito (isto é, "quem sou eu?"), dadas as inúmeras possibilidades de a linguagem escrita reformular os sentidos ontológicos da individualidade e da alteridade. Uma situação de aprendizagem, mediada pela "relação com a escrita", poderá traduzir-se, à luz desse princípio, numa situação profundamente subjetiva e pela qual o escritor trabalha na memória e na exploração narrativa de "um outro" ("fui eu quem escreveu isto?"). Nessa situação joga-se, portanto, uma exigência de tipo não só "escritural", mas sobretudo experiencial. Quererá isto dizer que, por meio de um trabalho de escrita no qual o sujeito se encontra no saber, tal trabalho permitirá refletir nos processos de autoria textual, bem como nos processos de leitura do produto escrito daí resultante. Perspectivar o sujeito (educando) enquanto autor dos seus produtos escritos é uma tarefa de natureza educativa que vem exigir processos diferentes de intertextualidade, os quais não parecem passar pelo domínio do cognitivo. $\bigcirc$ sujeito surge no centro de relações múltiplas com o saber, as quais são refletidas na situação de escrita. Nessa medida, e como nos foi testemunhado pelos escritores deste estudo ao considerarem que os "jovens escritores" deverão "abrir-se o mais possível às influências", tal pressuposto, se o quisermos olhar do ponto de vista educativo, faz-nos repensar o trabalho de intertextualidade pelo lado dos "amores", diria Deleuze (1995), evocando aqui as suas palavras ao referir-se às imagens do pensamento e ao aprender. 
[...] Nunca se sabe, de antemão, como alguém chegará a aprender - mediante que amores se chega a ser bom a latim, por meio de que encontros se chega a ser filósofo, ou em que dicionários se aprende a pensar [...] Não há nenhum método para encontrar tesouros e muito mais para aprender, mas uma violenta elevação, uma cultura ou uma paideia que percorre o indivíduo inteiramente [...] método é o moyen du savoir [do original] que regula a colaboração de todas as faculdades [...], a cultura é o movimento de aprender, a aventura do involuntário que encadeia uma sensibilidade, uma memória e, então, um pensamento. (DELEUZE, 1995, p. 165-166).

Nessa linha de ideias, o envolvimento dos escritores na problemática educativa vem retomar a questão do sentido dos processos de educação e formação artística, isto é, qual o sentido do trabalho à volta do patrimônio literário, encarando-se o literário na sua diversidade e enquanto movimento de saberes. Do ponto de vista dos escritores, é fundamental que as experiências educativas coloquem os alunos num diálogo com o valor estético e literário das obras, mas mais no sentido de os alunos "verem para além da própria literatura", lerem o que está para lá da literatura e que tem que ver justamente com o humano, nas suas complexas e diversas manifestações, imagens, forças e falhanços. Significa isto, portanto, que se torna necessário construir nos processos de educação artística uma cultura à volta dos saberes literários, cujo movimento estará para lá da ideia da literatura em si ou da sua suficiência enquanto "ferramenta" ou "recurso" para os processos de aprendizagem da língua. Será necessário, assim, assumir uma pertinência (e potência) entre o educativo e o literário enquanto campo de conhecimento, a partir do qual os leitores se produzem a si mesmos, sem ignorar a necessidade de inserir a "ideologia das obras", que continuamente se atravessa nas práticas escolares de escrita, no âmbito das práticas culturais, sociais e políticas das quais o conceito de "obra" resulta justamente enquanto tal. $\bigcirc$ trabalho com o patrimônio literário - e daí a relevância, julgamos, de retomar essa questão a partir dos escritores pode nessa medida ser visto como essencial para o campo educativo, na esteira do papel que as humanidades e as artes podem possuir no processo formativo mais vasto de qualquer pessoa. 


\section{REFERÊNCIAS}

BARTHES, R. Escritores, intelectuais, professores e outros ensaios. Lisboa: Presença, 1975.

BENJAMIN, W. Sobre arte, técnica, linguagem e política. Lisboa: Relógio d'Água, 1992.

DELEUZE, G. Difference and repetition. NY: Columbia University Press, 1995. Tradução de: Difference et Répétition.

DENZIN, N. Interpretative Interactionism. London: Sage Publications, 2001.

GADAMER, H.-G. Texto e Interpretação. In: BORGES-DUARTE, I.; HENRIQUES, F.; DIAS, I. M. (Org.). Texto, Leitura e Escrita. Porto: Porto Editora, 2000.

GENETTE, G. Palimpsests. La littérature au second degré. Paris: Éditions du Seuil, 1982.

LARROSA, J. B. Notas sobre a experiência e o saber da experiência. Revista Brasileira de Educação, n. 19, p. 20-28, jan./abr. 2002.

LARROSA, J. Pedagogia Profana. Danças, piruetas e mascaradas. Belo Horizonte: Autêntica, 1999.

NOGUEIRA, P. Escrita, escritores e "relação com a escrita». Para uma abordagam narrativa e biográfica em educação. Saarbrucken: Omniscriptum, 2015.

PENLOUP, M.-C. La tentation du littéraire. Essai sur le rapport à la l'écriture du scripteur "ordinaire». Paris: CREDIF Essais, 2000.

RICOEUR, P. Teoria da Interpretação. Lisboa: Edições 70, 1996.

RICOEUR, P. Time and Narrative - I. Chicago: University of Chicago Press, 1983.

Endereços para correspondência: Faculdade de Psicologia e de Ciências da Educação da Universidade do Porto, Rua Alfredo Allen, 4200-135, Porto, Portugal; pnogueira@fpce.up.pt 